\title{
Cytokine responses to two common respiratory pathogens in children are dependent on interleukin-1 $\beta$
}

\author{
Alice C-H. Chen ${ }^{1,9}$, Yang Xi ${ }^{1,9}$, Melanie Carroll ${ }^{1}$, Helen L. Petsky ${ }^{2}$, \\ Samantha J. Gardiner $\mathbb{1}^{2}$, Susan J. Pizzutto ${ }^{3}$, Stephanie T. Yerkovich $\mathbb{1}^{4}$, \\ Katherine J. Baines ${ }^{5}$, Peter G. Gibson ${ }^{5}$, Sandra Hodge ${ }^{6}$, Ian B. Masters ${ }^{7}$, \\ Helen M. Buntain ${ }^{8}$, Anne B. Chang ${ }^{2,3}$ and John W. Upham ${ }^{1}$
}

Affiliations: ${ }^{1}$ Diamantina Institute, The University of Queensland, Brisbane, Australia. ${ }^{2}$ Queensland University of Technology, CCHR, Brisbane, Australia. ${ }^{3}$ Child Health Division, Menzies School of Health Research, Charles Darwin Hospital, Darwin, Australia. ${ }^{4}$ The Prince Charles Hospital, Brisbane, Australia. ${ }^{5}$ The University of Newcastle, Newcastle, Australia. ${ }^{6}$ Hanson Institute, Adelaide, Australia. ${ }^{7}$ Respiratory and Sleep Medicine, Lady Cilento Children's Hospital, Brisbane, Australia. ${ }^{8}$ Wesley Hospital, Brisbane, Australia. ${ }^{9}$ These authors contributed equally.

Correspondence: John Upham, Translational Research Institute, 37 Kent St, Woolloongabba, QLD 4102, Australia. E-mail: j.uphamauq.edu.au

ABSTRACT Protracted bacterial bronchitis $(\mathrm{PBB})$ in young children is a common cause of prolonged wet cough and may be a precursor to bronchiectasis in some children. Although PBB and bronchiectasis are both characterised by neutrophilic airway inflammation and a prominent interleukin (IL)-1 $\beta$ signature, the contribution of the IL- $1 \beta$ pathway to host defence is not clear.

This study aimed to compare systemic immune responses against common pathogens in children with $\mathrm{PBB}$, bronchiectasis and control children and to determine the importance of the IL-1 $\beta$ pathway.

Non-typeable Haemophilus influenzae (NTHi) stimulation of peripheral blood mononuclear cells (PBMCs) from control subjects $(n=20)$, those with recurrent PBB $(n=20)$ and bronchiectasis $(n=20)$ induced high concentrations of IL-1 $\beta$, IL-6, interferon (IFN)- $\gamma$ and IL-10. Blocking with an IL-1 receptor antagonist (IL-1Ra) modified the cellular response to pathogens, inhibiting cytokine synthesis by NTHistimulated PBMCs and rhinovirus-stimulated PBMCs (in a separate PBB cohort). Inhibition of IFN- $\gamma$ production by IL-1Ra was observed across multiple cell types, including $\mathrm{CD} 3^{+} \mathrm{T}$ cells and $\mathrm{CD} 56^{+} \mathrm{NK}$ cells.

Our findings highlight the extent to which IL-1 $\beta$ regulates the cellular immune response against two common respiratory pathogens. While blocking the IL-1 $\beta$ pathway has the potential to reduce inflammation, this may come at the cost of protective immunity against NTHi and rhinovirus.

@ERSpublications

IL-1ß blockade limits infection response http://ow.ly/nCtE30eTbyg

Cite this article as: Chen $\mathrm{AC}-\mathrm{H}, \mathrm{Xi} \mathrm{Y}$, Carroll $\mathrm{M}$, et al. Cytokine responses to two common respiratory pathogens in children are dependent on interleukin-1ß. ERJ Open Res 2017; 3: 000252017 [https://doi.org/10.1183/23120541.00025-2017].

This article has supplementary material available from openres.ersjournals.com

Received: Feb 262017 | Accepted after revision: July 072017

Support statement: A.B. Chang and P.G. Gibson are supported by National Health and Medical Research Council (NHMRC) practitioner fellowships (grants 1058213 and 1058552). The study was supported by an NHMRC project grant (1042601) and a small grant from NHMRC CRE for Lung Health in Indigenous Children. A.C-H. Chen and H.L. Petsky are supported by postdoctoral fellowships funded by the NHMRC CRE for Lung Health in Indigenous Children (1040830). Funding information for this article has been deposited with the Crossref Funder Registry.

Conflict of interest: Disclosures can be found alongside this article at openres.ersjournals.com

Copyright $\odot$ ERS 2017. This article is open access and distributed under the terms of the Creative Commons Attribution Non-Commercial Licence 4.0. 


\section{Introduction}

Protracted bacterial bronchitis (PBB) is a common cause of chronic wet cough in preschool-aged children, characterised by the isolation of bacterial pathogens from the lower airways and clinical response to prolonged antibiotics $[1,2]$. While often responding to prolonged antibiotic treatment, untreated or recurrent $\mathrm{PBB}$ may progress to bronchiectasis $[3,4]$. Studying the immunobiology of PBB thus provides a unique opportunity to gain insight into the development of bronchiectasis. Our recent studies in this area have focused on Haemophilus influenzae and the cytokine interleukin (IL)-1ß.

In children with $\mathrm{PBB}$ and early-stage (or mild) bronchiectasis, the most common pathogen (up to 50\%) identified in the airways is $H$. influenzae [5-7]. H. influenzae is a Gram-negative bacterium that can be categorised into typeable and non-typeable (NTHi) strains based on the presence or absence of a polysaccharide capsule. Most strains of $H$. influenzae are opportunistic microbes that are part of the normal nasopharyngeal flora of most people. Some can result in bronchitis, pneumonia and otitis media. In subjects with chronic respiratory conditions, the acquisition of new strains may be associated with acute exacerbations of airway diseases [8]. However, factors that influence whether the acquisition of a $H$. influenzae strain results in disease or in asymptomatic colonisation are yet to be identified. The pathology caused by $H$. influenzae is often due to the pro-inflammatory responses of the host rather than the "virulence factors" of the bacteria [9].

Airway neutrophilia and activation of pulmonary innate immune pathways are frequently observed in children with PBB $[10,11]$. Lung cells produce many cytokines in PBB, yet IL-1 $\beta$ is particularly prominent in the $\mathrm{PBB}$ airways compared to healthy airways [12]. Although airway concentrations of IL-1 $\beta$ are strongly associated with symptom severity, it is not clear whether IL-1 $1 \beta$ contributes to PBB pathophysiology and is a potential therapeutic target, or whether IL- $1 \beta$ is important for the host defence against respiratory pathogens.

IL-1 $\beta$ is a pro-inflammatory cytokine that activates several inflammatory pathways, including the rapid recruitment of neutrophils to inflammatory sites, induction of cytokines and chemokines, and the activation of adaptive immunity [13]. The production of IL-1 $\beta$ by monocytes, macrophages and epithelial cells can be stimulated by bacterial infections, including $H$. influenzae [14]. The effects of IL-1 $\beta$ are controlled by several naturally occurring inhibitors, including the IL-1 receptor antagonist (IL-1Ra) [15]. However, the consequences of IL-1 $\beta$ inhibition in the setting of NTHi are not well understood.

The overall aim of our study was to determine the importance of IL-1 $\beta$ in children with chronic endobronchial suppuration (PBB and bronchiectasis). Specifically, in children with PBB and bronchiectasis (compared to controls), we aimed to 1) examine the extent to which circulating immune cells from these children with bronchiectasis produce IL-1 $\beta$ and other cytokines, spontaneously and in response to NTHi, and 2) evaluate the influence of IL-1 $\beta$ blockade on cytokine responses to NTHi. Parallel studies also examined the role of IL-1 $\beta$ blockade on cellular responses to human rhinovirus (RV), a common cause of viral respiratory infections in children.

\section{Methods}

\section{Subjects and procedures}

This study was approved by the Ethics Committees of Children's Health Queensland (HREC/03/QRCH/ 17), Queensland University of Technology (1400000072), and Uniting Care Health (1418), University of Queensland (2008000064 and 2008000037). Informed consent was obtained from all participants' parents or legal guardians. Diagnosis of recurrent PBB was based on a wet cough on the day of bronchoscopy, airway neutrophilia (>15\%) and $>3$ separate episodes of $\mathrm{PBB}$ within 12 months following bronchoscopy. Diagnosis of bronchiectasis was based on chest computed tomography (CT) using established criteria [16]. All children in the bronchiectasis cohort had non-cystic fibrosis (CF) bronchiectasis. Children in the control arm were excluded if they had any previous respiratory conditions. Medical histories were obtained for all, and parents of children with $\mathrm{PBB}$ and bronchiectasis also completed a cough diary [17] and were followed up for 12 months.

\section{PBMC isolation}

PBMCs were isolated from whole blood using Lymphoprep gradient media (Stemcell Technologies, Vancouver, Canada) and then cryo-preserved in liquid nitrogen. Experiments were carried out in batches. Thawed cells were rinsed twice in $2 \%$ heat-inactivated fetal calf serum/penicillin-streptomycin-glutamine/ RPMI and rested in culture medium at $37^{\circ} \mathrm{C} / 5 \% \mathrm{CO}_{2}$ for an hour before the experiment. PBMCs were plated in a 96-well U-bottom plate (In vitro Technologies, Noble Park North, Australia) at 250000 cells per well with 5\% HI-FCS/PSG/RPMI (LifeTechnologies, Carlsbad, CA) for $24 \mathrm{~h}$ culture, or 5\% autologous plasma for $72 \mathrm{~h}$ and 5 day cultures. 
Stimulation with NTHi and RV

A single clinical isolate of NTHi [18] and a laboratory strain of rhinovirus, RV1B [19], were used for all experiments and prepared as previously described. PBMCs were stimulated with NTHi (multiplicity of infection (MOI) of 0.33 ) or RV1B (MOI 1) for $24 \mathrm{~h}, 72 \mathrm{~h}$ or 5 days, and $500 \mathrm{ng} \cdot \mathrm{mL}^{-1}$ anakinra (Amgen, Thousand Oaks, CA) or $10 \mathrm{ng} \cdot \mathrm{mL}^{-1} \mathrm{IL}-1 \beta$ was used to pretreat cells for $1 \mathrm{~h}$ before stimulation with NTHi or RV1B in relevant experiments.

Cytokine quantification using ELISA

IL-1 $\beta$, IL-1Ra, IL-18, IL-6, interferon (IFN)- $\gamma$ and IL-10 in cell-free culture supernatant were measured by ELISA, as detailed in the supplementary material. Results are expressed as cytokine concentration per $1 \times 10^{6}$ cells.

\section{Enumeration of cell subsets and their cytokine response using flow cytometry}

Percentages of monocytes, natural killer (NK) cells, T-cells, non-T-cells, regulatory T-cells (Treg) and IFN $-\gamma^{+}$producing cells were evaluated using intracellular cytokine staining. Detailed cell surface staining and intracellular cytokine staining methods are detailed in the supplementary material. A total of approximately 200000 events were acquired using an LSRFortessa X-20 cell analyser (BD Bioscience, San Jose, CA). Data were analysed using the FlowJo Tree Star software (version 7.6.1). For intracellular cytokine staining, unstimulated background was subtracted from the data (for details, see supplementary material).

Outcome measures and data analysis

Data were analysed using non-parametric methods. Mann-Whitney U-tests were used to test the significance of differences between two study cohorts. Wilcoxon matched-pairs signed rank tests were used to test the significance of differences between unstimulated controls and microbes- or cytokine-stimulated groups. Statistical analyses were performed using PRISM software (version 6; GraphPad, La Jolla, CA, USA) and p-values $<0.05$ were considered significant.

\section{Results}

We approached our aims using PBMCs from children with recurrent PBB ( $n=20$ for the NTHi experiments and a separate group of $\mathrm{n}=13$ for the RV experiments), bronchiectasis $(\mathrm{n}=20)$ and controls $(n=20)$ (table 1). The ages and gender distribution were similar in the three study cohorts. Given our previous finding that IL- $1 \beta$ is prominent in $\mathrm{PBB}$, our experiments focused on IL-1 $\beta$ and related cytokines and the extent to which cytokine responses are influenced by IL-1 $\beta$ blockade.

\section{PBMCs from all groups of children respond to NTHi stimulation in a similar manner}

In the absence of additional stimuli, IL- $1 \beta$ secretion by PBMC from control, PBB and bronchiectasis (BE) children was generally below the threshold of detection $\left(<3.9 \mathrm{pg} \cdot \mathrm{mL}^{-1}\right)$, while IL-1Ra, IL-18 and IL-6 were readily detected, even in the absence of in vitro stimulation (figure 1). Unstimulated PBMCs from PBB children produced less IL-18 and more IL-10 than PBMCs from healthy subjects $(\mathrm{p}<0.01$ and $\mathrm{p}<0.05$, respectively) and this difference was independent of age, cough score or airway bacterial load ( $p>0.05$ by multivariate analysis) (table S1).

\section{TABLE 1 Subject demographics and full blood counts}

\begin{tabular}{|c|c|c|c|c|}
\hline & Controls" & Recurrent PBB ${ }^{\#}$ & Recurrent PBBף & Bronchiectasis" \\
\hline Subjects $\mathrm{n}$ & 20 & 20 & 13 & 20 \\
\hline Age years & $2.2(0.3-4.5)$ & $1.6(0.9-2.8)$ & $3.2(1.6-6.1)$ & $3.1(2.1-5.0)$ \\
\hline Boys n & $15(75 \%)$ & $16(80 \%)$ & $9(70 \%)$ & $14(70 \%)$ \\
\hline Cough score & NA & $3(1-3)$ & $3(1-4)$ & $2(1-3)$ \\
\hline \multicolumn{5}{|c|}{ Full blood count $\times 10^{6} \mathrm{~L}^{-1}$} \\
\hline Total cell count & $8.90(8.18-10.2)$ & $11.0(9.05-12.2)$ & 9.30 (8.25-10.3) & $9.60(7.70-11.8)$ \\
\hline Neutrophils & $2.88(1.69-3.72)$ & $3.63(2.49--4.96)$ & 2.55 (2.13-3.09) & $2.96(2.44-4.26)$ \\
\hline Monocytes & $0.80(0.59-1.02)$ & $1.09(0.78-1.16)$ & $0.71(0.63-0.94)$ & $0.84(0.69-0.96)$ \\
\hline Eosinophils & $0.34(0.12-0.67)$ & $0.38(0.19-0.59)$ & $0.22(0.17-0.67)$ & $0.35(0.24-0.74)$ \\
\hline Lymphocytes & $4.82(3.81-5.87)$ & $5.32(4.04-6.60)$ & $4.97(3.99-5.97)$ & $4.51(3.83-5.81)$ \\
\hline
\end{tabular}

Data are presented as median (interquartile range) unless otherwise stated. PBB: protracted bacterial bronchitis; IQR: interquartile range; NA: not applicable. " ${ }^{\#}$ figures 1 and 2 ; ${ }^{\text {" : figures }} 3$ and 4. 
We stimulated PBMCs with a single clinical isolate of NTHi [18] for $24 \mathrm{~h}$ or $72 \mathrm{~h}$ to examine the innate and adaptive cytokine responses to this organism. PBMCs from all control, PBB and bronchiectasis subjects were highly responsive to low-dose NTHi stimulation $\left(0.2 \times 10^{6} \mathrm{cfu} \cdot \mathrm{mL}^{-1}\right)$, producing large amounts of innate and adaptive cytokines including IL-1 $\beta$, IL-6, IFN- $\gamma$ and IL-10 $(p<0.001$ for all comparisons between unstimulated and NTHi-stimulated cultures) (figure 1). The concentration of IL-18, another IL-1 family cytokine, appeared to fall after NTHi stimulation (26\% and $40 \%$ decrease in control and $\mathrm{PBB}$ at $24 \mathrm{~h}, \mathrm{p}<0.01$ for both). The IL- $1 \beta$ antagonist IL-1Ra was always present at higher concentrations than IL-1 $\beta$ across all cell populations studied and NTHi stimulation did not alter its concentration at $24 \mathrm{~h}$ post stimulation.

\section{IL-1 blockade inhibits NTHi-induced cytokine production}

In order to examine the impact that secreted IL-1 $\beta$ might have on other immune responses to NTHi, we employed an IL-1 receptor antagonist (IL-1Ra or anakinra) to block the biological activity of IL-1. Anakinra significantly inhibited IL-6 production (in control, PBB and bronchiectasis PBMCs, respectively;
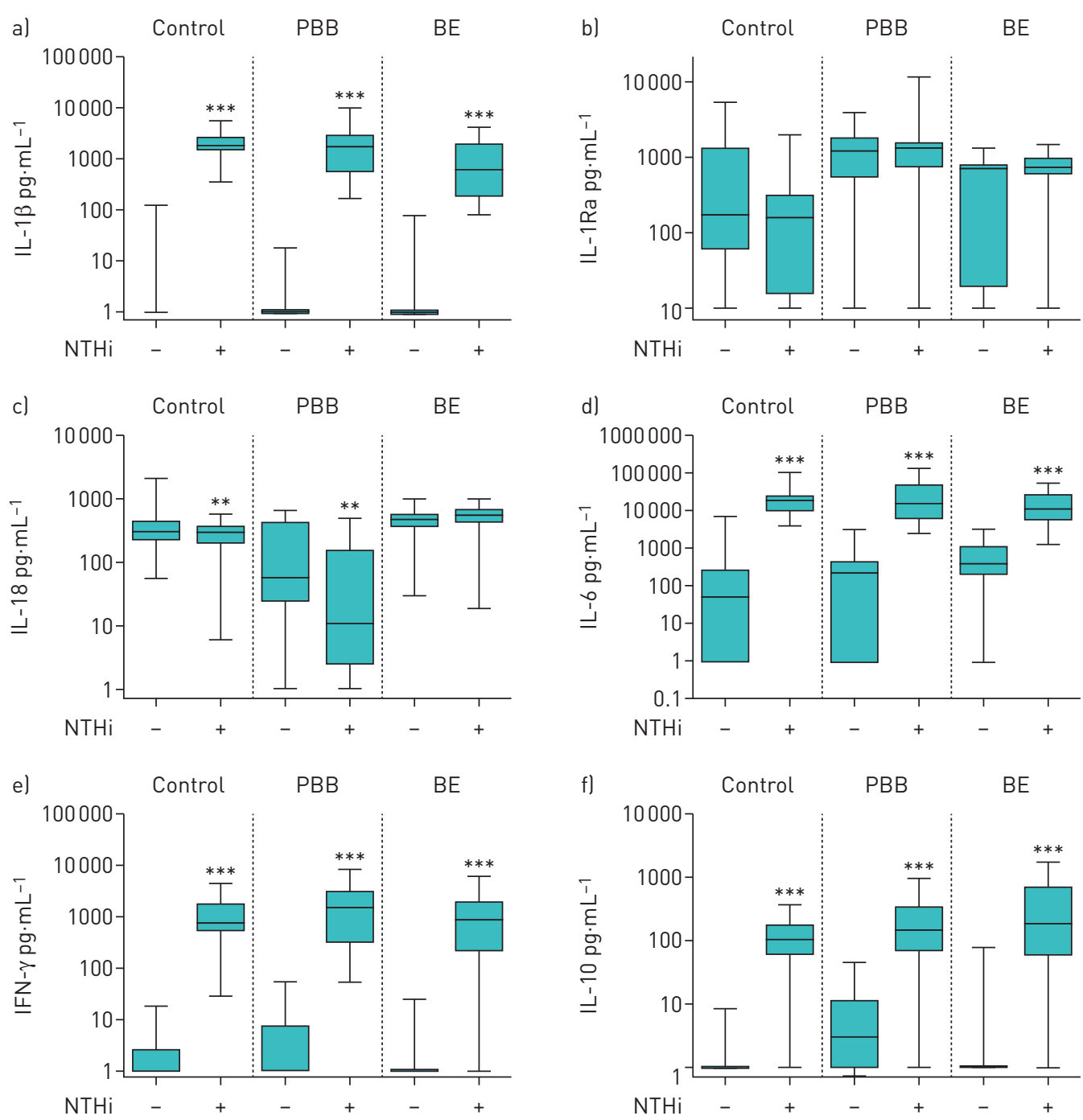

FIGURE 1 Non-typeable Haemophilus influenzae (NTHi)-stimulated cytokine production. Peripheral blood mononuclear cells from healthy control children $(n=17)$, children with protracted bacterial bronchitis (PBB) $(n=19)$ and children with bronchiectasis $(B E)(n=20)$ were cultured ex vivo in the presence of NTHi. Supernatant was collected at $24 \mathrm{~h}$ for the innate response cytokines (interleukin (IL)-1 $\beta$, interleukin-1 receptor antagonist (IL-1Ra), IL-18 and IL-6) and at $72 \mathrm{~h}$ for the adaptive response cytokines (interferon (IFN)- $\gamma$ and IL-10). a) IL-1 $\beta$ concentration. b) IL-1Ra concentration. c) IL-18 concentration. d) IL-6 concentration. e) IFN- $\gamma$ concentration. f) IL-10 concentration. Box and whisker plots display median, interquartile ranges and range. **: $p<0.01$ by Wilcoxon matched-pairs signed rank test; ${ }^{* * *}: p<0.001$ by Wilcoxon matched-pairs signed rank test. 
$\mathrm{p}<0.01$ for all), IFN- $\gamma$ production (in control, PBB and bronchiectasis PBMCs, respectively; $\mathrm{p}<0.01$ for all) and IL-10 production (in control, PBB and bronchiectasis PBMCs, respectively; $\mathrm{p}<0.001$ for all) (figure 2). Blockade of IL-1 biological activity also inhibited IL- $\beta$ production in controls $(\mathrm{p}<0.05)$ and $\mathrm{PBB}$ $(\mathrm{p}<0.001)$ PBMCs. No consistent effect on IL-18 production was observed.

\section{IL-1 blockade inhibits RV1B-induced cytokine production}

To determine if similar findings would also be observed with a common respiratory virus, we repeated the experiment using a clinical isolate of human rhinovirus, RV1B, using PBMCs from a separate group of 13 children with PBB. RV1B increased the production of IL-1Ra $(\mathrm{p}<0.01)$, IL-6 $(\mathrm{p}<0.05)$, IFN- $\gamma(\mathrm{p}<0.01)$ and IL-10 ( $\mathrm{p}<0.01$ ), while IL-1 $\beta$ and IL-18 production remained at similar levels (figure 3 ). The addition of anakinra significantly inhibited RV1B-induced IL-6 production $(\mathrm{p}<0.05)$ and IFN- $\gamma$ production $(\mathrm{p}<0.05)$, but no consistent effect was observed in IL-1 $\beta$ and IL-10 protein synthesis (figure 4).

a)
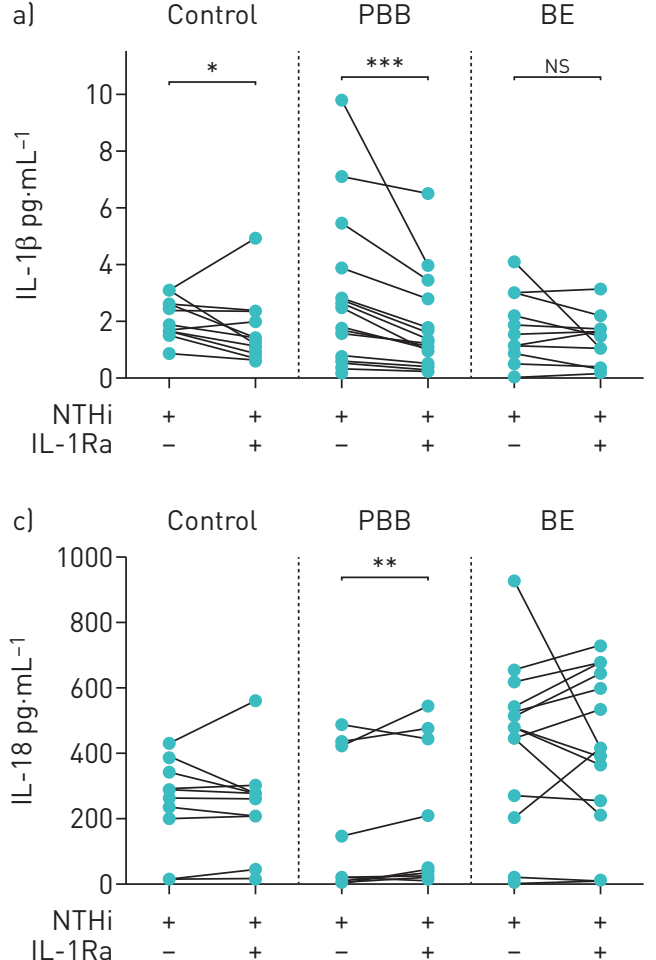

b) Contro

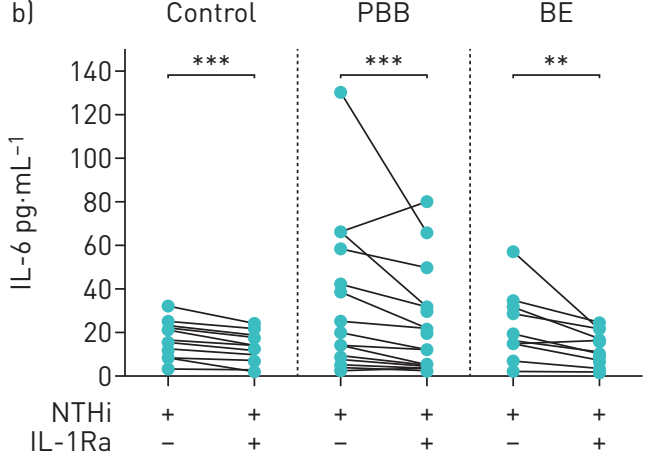

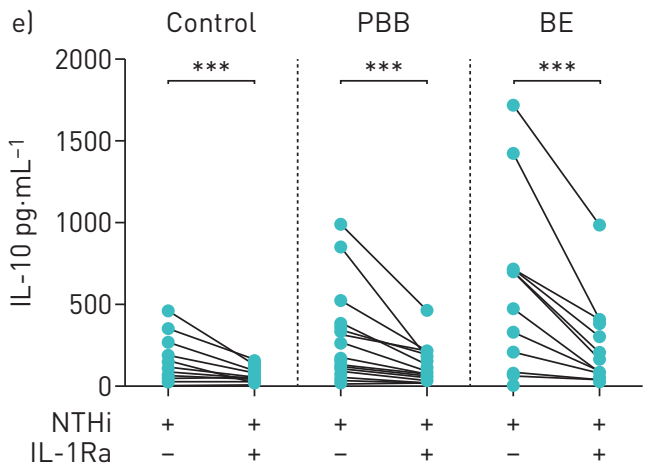

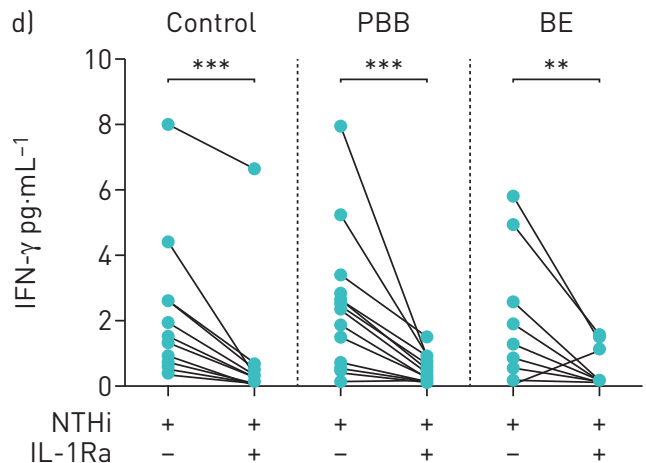

FIGURE 2 Effects of interleukin-1 receptor antagonist (IL-1Ra) on peripheral blood mononuclear cell (PBMC) responses to non-typeable Haemophilus influenzae (NTHi). PBMCs were cultured ex vivo with NTHi in the presence or absence of the IL-1Ra anakinra. Data are from 14-15 healthy control children, 17-19 children with protracted bacterial bronchitis (PBB) and 12-13 children with bronchiectasis (BE). a) Interleukin (IL)-1 $\beta$ concentration. b) IL-6 concentration. c) IL-18 concentration. d) IFN- $\gamma$ concentration. e) IL-10 concentration. NS: nonsignificant. ${ }^{*}: p<0.05$ by Wilcoxon matched-pairs signed rank test; ${ }^{* *}$ : $p<0.01$ by Wilcoxon matched-pairs signed rank test; ${ }^{* * *}: p<0.001$ by Wilcoxon matched-pairs signed rank test. 
IL-1 $\beta$ increases NTHi- and RV1B-induced cytokine production

More detailed experiments to examine the effects of IL-1 $\beta$ on NTHi- and RV1B-induced cytokine production were not possible with the small number of PBMCs available from the children described above. Accordingly, we used PBMCs from healthy adults (age $>18$ years, no current or history of respiratory diseases) to perform the following experiments. Exogenous IL-1 $\beta\left(10 \mathrm{ng} \cdot \mathrm{mL}^{-1}\right)$ markedly enhanced RV1B-induced IL-6, IFN- $\gamma$ and IL-10 production $(\mathrm{p}<0.05, \mathrm{p}<0.001$ and $\mathrm{p}<0.001$, respectively) (figure 5). The addition of exogenous IL-1 $\beta$ also increased NTHi-induced IL-6 $(p<0.05)$. The presence of IL- $1 \beta$ alone was able to induce IL-6, IFN- $\gamma$ and IL-10 production in the absence of microbial stimulation.

\section{IL-1 blockade effects IFN- $\gamma$ production by multiple cell types}

Flow cytometry was used to identify the cell populations activated by NTHi and RV in the presence or absence of anakinra. Blocking the biological activity of IL-1 did not change the proportion of cell populations in RV1B-stimulated healthy adult PBMCs (figure S1). Stimulation with NTHi induced minor changes in the percentage of monocytes, $\mathrm{CD} 4^{-} \mathrm{T}$-cells, $\mathrm{CD} 3^{-} \mathrm{CD} 56^{-} \mathrm{CD} 14^{-}$cells and $\mathrm{CD} 4^{+} \mathrm{T}$-cells, and this was modified slightly by anakinra. Intracellular cytokine staining confirmed that IL-1 blockade significantly inhibited the percentage of NTHi-stimulated IFN- $\gamma$-producing cells (figure 6) and that this inhibition was seen to a similar extent across $\mathrm{CD}^{+} 6^{+} \mathrm{NK}$ cells, $\mathrm{CD}^{+}$T-cells and other $\left(\mathrm{CD}^{-} 6^{-} \mathrm{CD}^{-}\right)$ cells $(\mathrm{p}<0.05$ for all).

\section{Discussion}

Our previous findings that IL- $1 \beta$ and its associated pathway are prominent in the airways of children with $\mathrm{PBB}$, relative to healthy children [12], led us to examine cell-mediated immunity to NTHi and the effects of IL-1 $\beta$ inhibition. Our key findings are as follows. Firstly, NTHi-activated PBMCs from PBB and bronchiectasis children can readily produce IL-1 $\beta$ and other cytokines, with similar responses to those seen in healthy age-matched children. Secondly, blocking the biological activity of IL-1 $\beta$ inhibits NTHi-induced cytokine production in multiple cell types, suggesting that IL-1 $\beta$ is an important driver of the innate and adaptive immune response to NTHi. Thirdly, blocking the biological activity of IL-1 $\beta$ also inhibits RV1B-induced IL- 6 and IFN- $\gamma$ production. Finally, we have shown that adding exogenous IL- $1 \beta$ also enhances IL-6, IFN- $\gamma$ and IL-10 production upon RV1B stimulation.
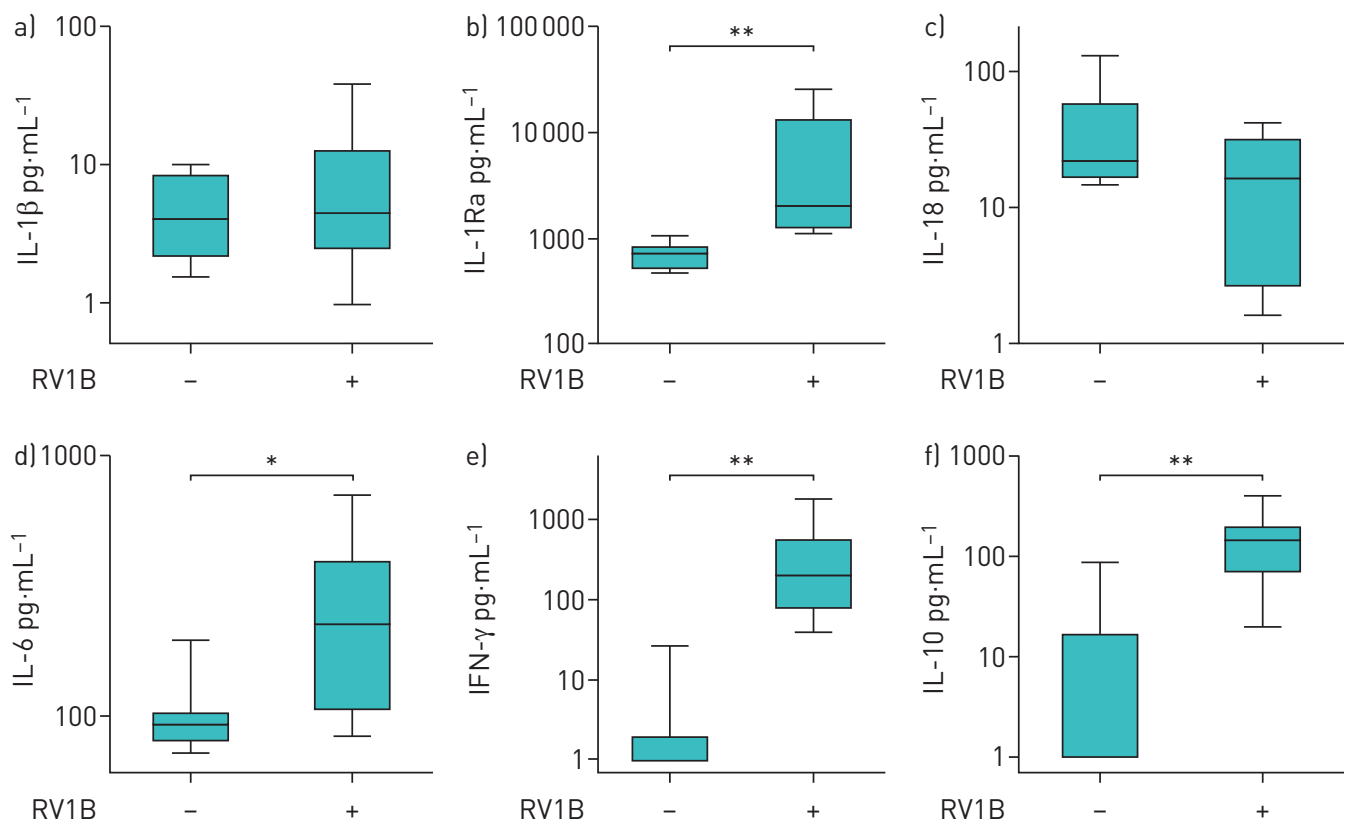

FIGURE 3 Rhinovirus (RV)1B-stimulated cytokine production. Peripheral blood mononuclear cells from children with protracted bacterial bronchitis (PBB) were cultured ex vivo in the presence of RV1B. Supernatant was collected at $24 \mathrm{~h}$ for the innate response cytokines (interleukin (IL)-1 $\beta$, interleukin-1 receptor antagonist (IL-1Ra), IL-18 and IL-6) and at $72 \mathrm{~h}$ for the adaptive response cytokines (interferon (IFN)- $\gamma$ and IL-10). a) IL-1 $\beta$ concentration ( $n=10)$. b) IL-1Ra concentration ( $n=10)$. c) IL-18 concentration $(n=6)$. d) IL-6 concentration $(n=10)$. e) IFN- $\gamma$ concentrations $(n=8)$. f) IL-10 concentration $(n=8)$. Box and whisker plots display median, interquartile ranges and range. ${ }^{*}: p<0.05$ by Wilcoxon matched-pairs signed rank test; ${ }^{* *} p<0.01$ by Wilcoxon matched-pairs signed rank test. 
We previously found that IL-1 $\beta$ and others members of the IL-1 pathway are expressed to a much greater extent in the airways of children with $\mathrm{PBB}$ than in control children and this is significantly associated with clinical outcomes [12]. This observation was not only found in children, but also in adults with chronic respiratory diseases, in which elevated IL-1 $\beta$ has been linked to poor lung function and the presence of pathogenic bacteria in non-CF bronchiectasis $[20,21]$. Our current study, the first such study in children, adds to these findings by showing that high IL- $1 \beta$ production is not a feature of circulating immune cells prior to their recruitment to the lung. Indeed, it appears that systemic cellular immune function is similar in PBB and healthy children, with cells from both groups of children showing virtually no "constitutive" IL- $1 \beta$ production, but having the capacity to produce large amounts of IL-1 $\beta$ and other cytokines when challenged with NTHi in vitro.

In the context of infection or tissue inflammation, the biological effects of IL-1 on target cells are modulated by the production of IL-1Ra, which is typically present at considerably greater concentrations [22]. Both the overproduction of IL-1 and/or underproduction of IL-1Ra may influence the course of different infectious diseases and predispose to the development of disease. Low concentrations of IL-1Ra in the bronchoalveolar lavage (BAL) of patients with early adult respiratory distress syndrome are associated with a poor prognosis, while a high ratio of IL-1Ra to IL-1 in BAL is associated with better outcomes in pulmonary sarcoidosis and cavitary pulmonary tuberculosis [23-25]. In the current study, the concentration of IL-1Ra was invariably higher than the concentration of IL-1 $\beta$ across all cell types. Interestingly, IL-1Ra concentration was elevated upon RV1B stimulation, but not NTHi stimulation, suggesting that RV infection may play a role in shaping the host defence mechanism via this IL-1Ra pathway.

Given that elevated IL-1 $\beta$ concentration is highly associated with symptom severity, disease recurrence and the intensity of airway inflammation $[12,21]$, IL-1 $\beta$ might be a therapeutic target in these conditions. However, our findings suggest that blocking the biological activity of IL-1 $\beta$ may have unintended consequences, reducing the ability of newly recruited T-cells, NK cells and other cells to produce IL-6, IFN- $\gamma$ and IL-10. Although we acknowledge that some experiments were performed with cells from healthy adults, we have no reason to believe that similar findings would not hold true with cells from children stimulated with a variety of pathogens. Blocking the biological activity of IL-1 $\beta$ has the potential to impair the capacity to generate optimal host defence via an adaptive recall/memory immune response
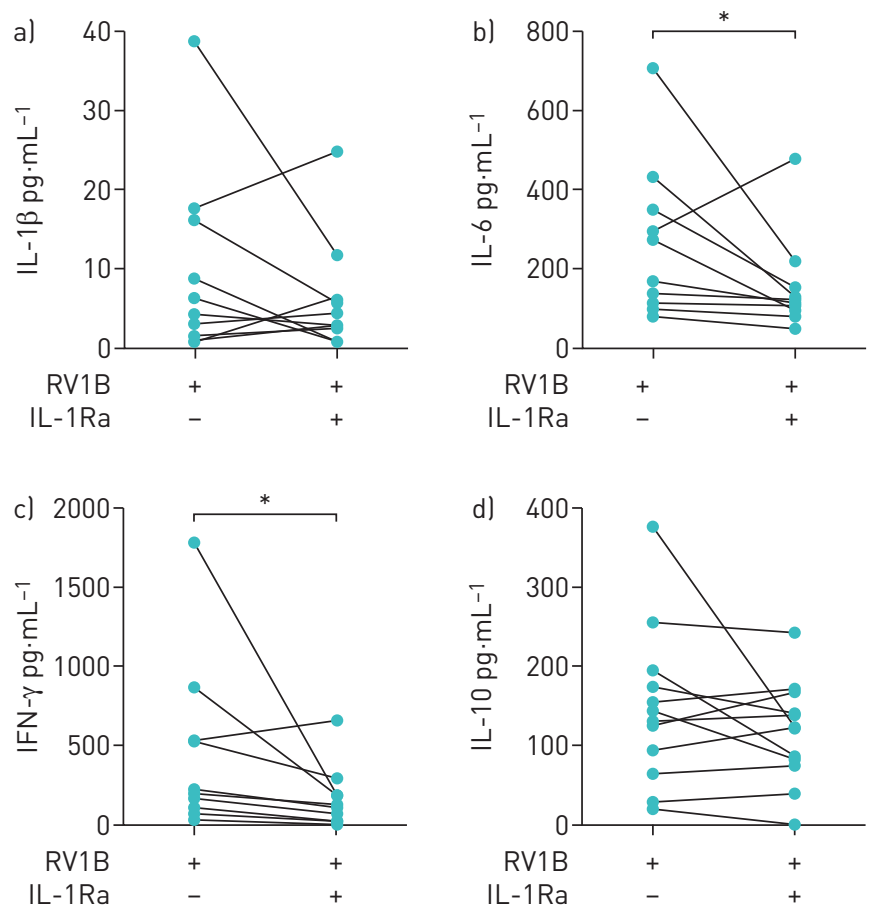

FIGURE 4 Effects of interleukin-1 receptor antagonist (IL-1Ra) on peripheral blood mononuclear cell (PBMC) responses to rhinovirus (RV)1B. PBMCs from children with protracted bacterial bronchitis (PBB) were cultured ex vivo with RV1B in the presence or absence of the IL-1Ra anakinra. a) Interleukin (IL)-1 $\beta$ concentration ( $n=11)$. b) IL-6 concentration ( $n=11)$. c) Interferon (IFN)- $\gamma$ concentration ( $n=12)$. d) IL-10 concentration $(n=12){ }^{*}$ : $p<0.05$ by Wilcoxon matched-pairs signed rank test. 

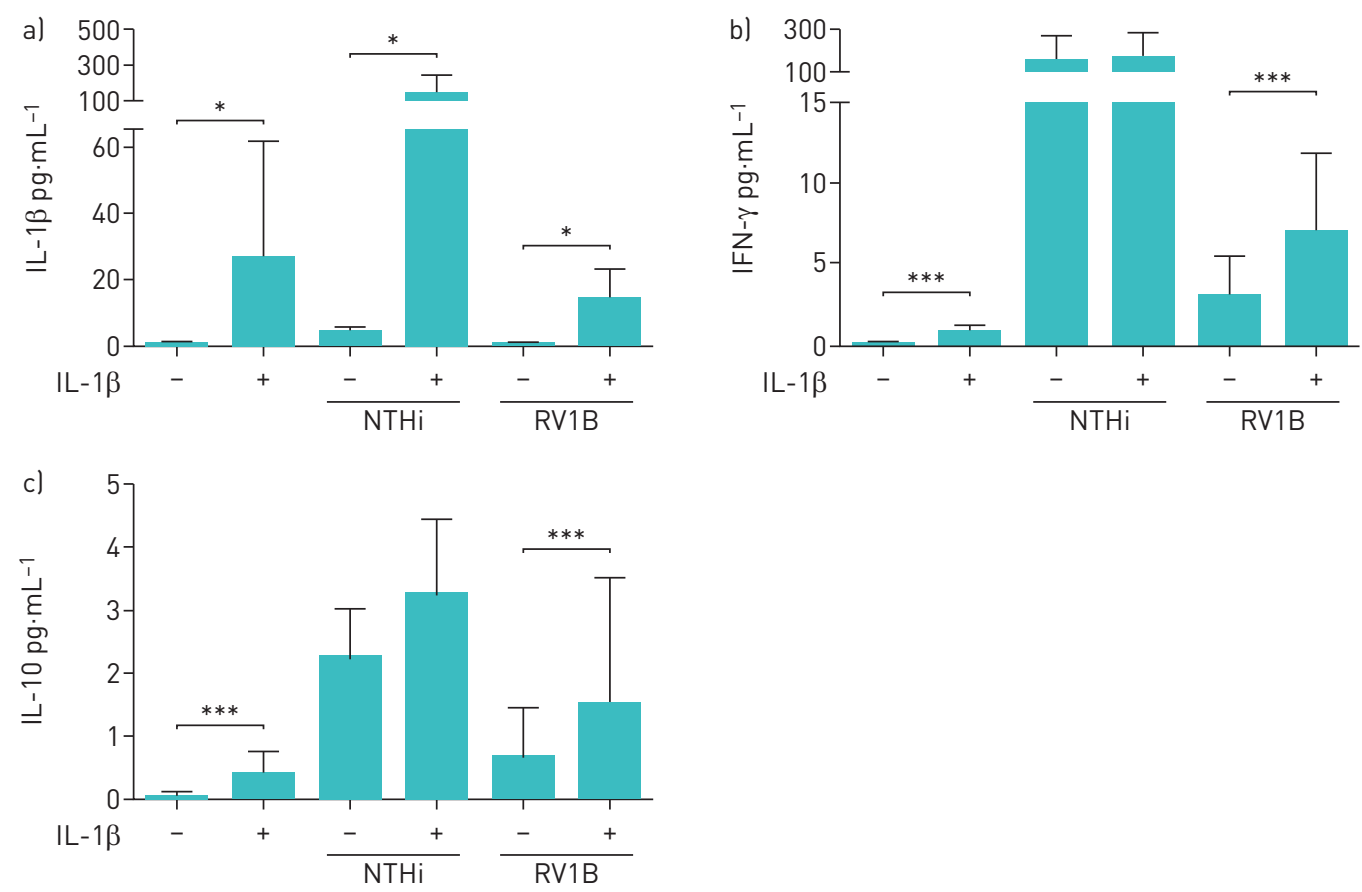

FIGURE 5 Effects of interleukin (IL)-1 $\beta$ on peripheral blood mononuclear cell (PBMC) responses to non-typeable Haemophilus influenzae (NTHi) and rhinovirus (RV)1B. PBMCs from healthy adults were cultured with NTHi or RV1b in the presence or absence of recombinant IL-1 $\beta$. Data are from 7-14 experiments. a) IL-6 concentration (n=7). b) Interferon (IFN)- $\gamma$ concentration. c) IL-10 concentration. Mean and standard deviations are shown. ${ }^{*}: p<0.05$ by Wilcoxon matched-pairs signed rank test; ${ }^{* *}: p<0.001$ by Wilcoxon matched-pairs signed rank test.

against both NTHi, RV and possibly other pathogens. Notably, there is strong evidence that rheumatoid arthritis patients treated with an IL-1 receptor antagonist are more susceptible to bacterial infection [24].

The factors leading to the development of bronchiectasis in early life are poorly understood, though it is recognised that PBB may be a precursor of bronchiectasis $[1,26]$ and thus worthy of detailed study. Poor antibacterial responses, poor antiviral responses and poor infection clearance have been thought to contribute to the pathogenesis of PBB and bronchiectasis. NTHi-stimulated PBMCs from young children with chronic suppurative lung disease, a condition related to $\mathrm{PBB}$, exhibit a lower capacity to produce IFN- $\gamma$ than healthy children [18]; this low NTHi-driven IFN- $\gamma$ production was associated with high IL- $1 \beta$ and IL-6 in the airways [27]. Here, we have shown that NTHi induces similar levels of innate and adaptive cytokine production in all subjects, suggesting that systemic cellular immune function is normal in $\mathrm{PBB}$ and bronchiectasis. Interestingly, IL-18 concentration appeared to be reduced in NTHi-stimulated PBMCs. A previous study in IL-18 knockout mice demonstrated that IL-18 is essential for airway NTHi clearance [28]. In humans, IL-18 is not only produced by migratory immune cells, but also by airway epithelial cells. Our preliminary experiments using a human airway epithelial cell line indicate that NTHi can induce a robust IL-18 response (figure S2). Therefore, the role of IL-18 in an NTHi infection is very cell type specific, and how reduced IL-18 production by PBMCs regulates the immune microenvironment upon NTHi infection is worth further investigation.

This is the first study comparing the response of PBMCs from healthy, PBB and bronchiectasis children to clinical strains of NTHi and RV. By using common bacteria and viruses found in paediatric airway diseases, we have examined how circulating immune cells respond to common respiratory infections in children with PBB and bronchiectasis. Due to the small specimen volumes from these young children, we were not able to use the same specimen/donor to test both the NTHi and RV1B responses. However, the subject demographics were well matched between study cohorts, and consistent findings have been reported. Although it would have been ideal to perform experiments with BAL T-cells and NK cells from children, this was not possible given the small numbers of cells obtained. Lung T-cells and NK cells are derived from the circulation, so studying PBMCs provides some information on the function of these cells prior to their recruitment to the lung. Culturing PBMCs with NTHi or RV in the presence of IL- $1 \beta$ (figure 5) also provides insight into how newly recruited cells respond to these pathogens in an IL-1 $\beta$-rich environment, thereby modelling what may be occurring in the diseased lung. We acknowledge that very 

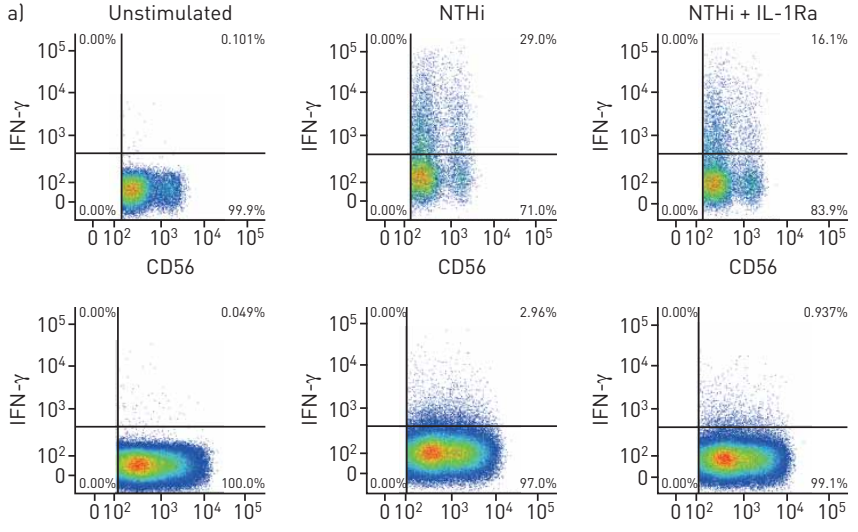

$\mathrm{CD} 3$
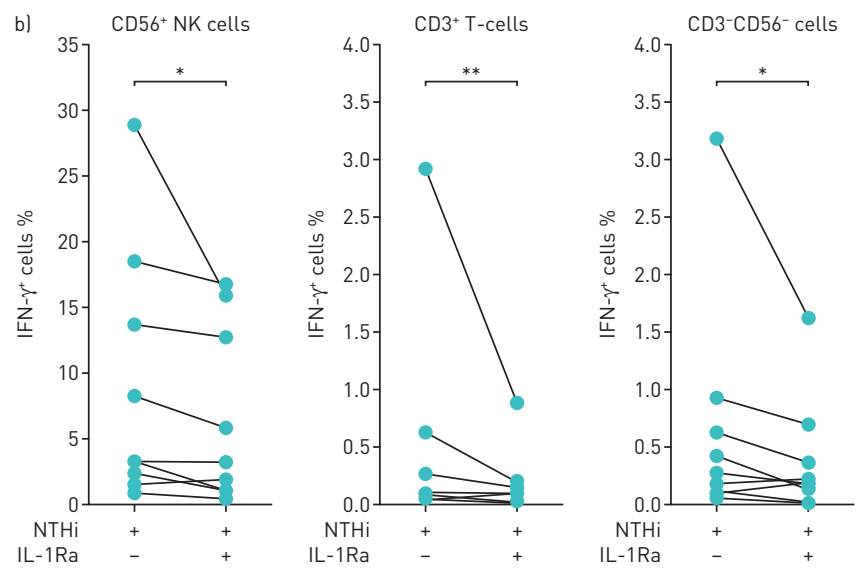

FIGURE 6 Interleukin-1 blockade effects interferon (IFN)- $\gamma$ production by multiple cell types. a) Gating strategy for flow cytometry: CD56 ${ }^{+}$natural killer (NK) cells $\left(\mathrm{CD}^{-}{ }^{-} \mathrm{CD} 56^{+}\right), \mathrm{CD}^{+}{ }^{+}$-cells $\left(\mathrm{CD}^{+} \mathrm{CD}^{-} 6^{-}\right)$and other cells $\left(\mathrm{CD} 3^{-} \mathrm{CD}^{-} 6^{-}\right)$were identified within the total gated lymphocytes. The percentage of IFN- $\gamma$-producing cells was then evaluated in each of the cell subtypes. b) Percentage of non-typeable Haemophilus influenzae (NTHi)-stimulated IFN- $\gamma$-producing cells in the absence and presence of interleukin-1 receptor antagonist (IL-1Ra) at $24 \mathrm{~h}$ post-stimulation (n=9). *: $p<0.05$ by Wilcoxon matched-pairs signed rank test; ${ }^{* *}$ : $p<0.01$ by Wilcoxon matched-pairs signed rank test.

little is known about the role of RVs in PBB. The RV experiments outlined herein were included in order to determine whether the immune regulatory properties of IL- $1 \beta$ are specific to NTHi, or are also shared with another respiratory pathogen. Future studies are needed to assess whether RVs, and altered immune responses to RVs, might be relevant to $\mathrm{PBB}$.

Our study highlights several important new features seen in PBB and bronchiectasis in children. In summary, circulating immune cells in children with $\mathrm{PBB}$ and bronchiectasis generate a cytokine response to common bacterial and viral infections, similar to that seen in healthy children. Although IL-1 $\beta$ concentration is elevated in $\mathrm{PBB}$ and bronchiectasis airways, it seems to be essential for an adequate immune response against bacterial and viral infection, so blocking IL-1 $\beta$ production or activity does not seem to be a desirable strategy. Dissecting the mechanisms responsible for such findings is likely to be pivotal in understanding the pathophysiology of $\mathrm{PBB}$ and may shed light on why some children progress to bronchiectasis, while others recover following antibiotic treatment.

\section{Acknowledgements}

The authors thank all the children and their parents who participated in this study. The authors also thank Christopher Bourke and Nitin Kapur for allowing us to recruit their patients into the study, Victoria Timbrell and Kelly Wong for their assistance with processing the specimens, and Greg Hodge for proofreading the manuscript.

A.C-H. Chen, Y. Xi, M. Carroll, K.J. Baines, P.G. Gibson, S. Hodge, I.B. Masters, H.M. Buntain, A.B. Chang and J.W. Upham conceived and design this study; A.C-H. Chen, Y. Xi, M. Carroll, H.L. Petsky, S.J. Gardiner, and S.T. Yerkovich acquired the data; A.C-H. Chen, Y. Xi, STY, A.B. Chang and J.W. Upham analysed and interpreted the data; A.C-H. Chen, Y. Xi, H.L. Petsky, S.T. Yerkovich, A.B. Chang and J.W. Upham drafted the manuscript and were responsible for important intellectual content; and all authors approved the final version for publication.

\section{References}

1 Chang AB, Upham JW, Masters IB, et al. Protracted bacterial bronchitis: the last decade and the road ahead. Pediatr Pulmonol 2016; 51: 225-242.

2 Wurzel DF, Marchant JM, Yerkovich ST, et al. Protracted bacterial bronchitis in children: natural history and risk factors for bronchiectasis. Chest 2016; 150: 1101-1108.

3 McShane PJ, Naureckas ET, Tino G, et al. Non-cystic fibrosis bronchiectasis. Am J Respir Crit Care Med 2013 188: 647-656.

4 Chang AB, Redding GJ, Everard ML. Chronic wet cough: protracted bronchitis, chronic suppurative lung disease and bronchiectasis. Pediatr Pulmonol 2008; 43: 519-531.

5 Marchant JM, Masters IB, Taylor SM, et al. Evaluation and outcome of young children with chronic cough. Chest 2006; 129: 1132-1141.

6 Kompare M, Weinberger M. Protracted bacterial bronchitis in young children: association with airway malacia. J Pediatr 2012; 160: 88-92.

7 Kapur N, Grimwood K, Masters IB, et al. Lower airway microbiology and cellularity in children with newly diagnosed non-CF bronchiectasis. Pediatr Pulmonol 2012; 47: 300-307.

8 Sethi S, Evans N, Grant BJ, et al. New strains of bacteria and exacerbations of chronic obstructive pulmonary disease. N Engl J Med 2002; 347: 465-471.

9 Erwin AL, Smith AL. Nontypeable Haemophilus influenzae: understanding virulence and commensal behavior. Trends Microbiol 2007; 15: 355-362.

10 Chang AB, Yerkovich ST, Gibson PG, et al. Pulmonary innate immunity in children with protracted bacterial bronchitis. J Pediatr 2012; 161: 621-625 e621. 
11 Marchant JM, Gibson PG, Grissell TV, et al. Prospective assessment of protracted bacterial bronchitis: airway inflammation and innate immune activation. Pediatr Pulmonol 2008; 43: 1092-1099.

12 Baines KJ, Upham JW, Yerkovich ST, et al. Mediators of neutrophil function in children with protracted bacterial bronchitis. Chest 2014; 146: 1013-1020.

13 Gabay C, Lamacchia C, Palmer G. IL-1 pathways in inflammation and human diseases. Nat Rev Rheumatol 2010; 6: $232-241$.

14 Rotta Detto Loria J, Rohmann K, Droemann D, et al. Nontypeable Haemophilus influenzae infection upregulates the NLRP3 inflammasome and leads to caspase-1-dependent secretion of interleukin-1 $\beta$ - a possible pathway of exacerbations in COPD. PLoS ONE 2013; 8: e66818.

15 Arend WP. The balance between IL-1 and IL-1Ra in disease. Cytokine Growth Factor Rev 2002; 13: 323-340.

16 Goyal V, Grimwood K, Marchant J, et al. Pediatric bronchiectasis: no longer an orphan disease. Pediatr Pulmonol 2016; 51: 450-469.

17 Chang AB, Newman RG, Carlin JB, et al. Subjective scoring of cough in children: parent-completed vs child-completed diary cards vs an objective method. Eur Respir J 1998; 11: 462-466.

18 Pizzutto SJ, Yerkovich ST, Upham JW, et al. Children with chronic suppurative lung disease have a reduced capacity to synthesize interferon- $\gamma$ in vitro in response to non-typeable Haemophilus influenzae. PLoS ONE 2014; 9: e104236.

19 Pritchard AL, White OJ, Burel JG, et al. Asthma is associated with multiple alterations in anti-viral innate signalling pathways. PLoS ONE 2014; 9: e106501.

20 Rogers GB, Zain NM, Bruce KD, et al. A novel microbiota stratification system predicts future exacerbations in bronchiectasis. Ann Am Thorac Soc 2014; 11: 496-503.

21 Chen AC, Martin ML, Lourie R, et al. Adult non-cystic fibrosis bronchiectasis is characterised by airway luminal Th17 pathway activation. PLoS ONE 2015; 10: e0119325.

22 Arend WP, Welgus HG, Thompson RC, et al. Biological properties of recombinant human monocyte-derived interleukin 1 receptor antagonist. J Clin Invest 1990; 85: 1694-1697.

23 Rubbert-Roth A. Assessing the safety of biologic agents in patients with rheumatoid arthritis. Rheumatology (Oxford) 2012; 51: Suppl. 5, v38-v47.

24 Salliot C, Dougados M, Gossec L. Risk of serious infections during rituximab, abatacept and anakinra treatments for rheumatoid arthritis: meta-analyses of randomised placebo-controlled trials. Ann Rheum Dis 2009; 68: 25-32.

25 Brassard P, Kezouh A, Suissa S. Antirheumatic drugs and the risk of tuberculosis. Clin Infect Dis 2006; 43: 717-722.

26 Chang AB, Grimwood K, Gibson PG, et al. PBB: definition, mechanisms, and treatment. Lancet Respir Med 2015; 3: $743-744$.

27 Pizzutto SJ, Upham JW, Yerkovich ST, et al. High pulmonary levels of IL-6 and IL-1 $\beta$ in children with chronic suppurative lung disease are associated with low systemic IFN- $\gamma$ production in response to non-typeable Haemophilus influenzae. PLoS ONE 2015; 10: e0129517.

28 Wieland CW, Florquin S, van der Poll T. Interleukin 18 participates in the early inflammatory response and bacterial clearance during pneumonia caused by nontypeable Haemophilus influenzae. Infect Immun 2007; 75 : 5068-5072. 